\title{
Mental retardation in younger children
}

\author{
Grishma Shukla" ${ }^{*}$, Swati B Thakur ${ }^{1}$, GT Swamy ${ }^{2}$, MV Rao ${ }^{1}$ \\ From International Conference on Human Genetics and 39th Annual Meeting of the Indian Society of \\ Human Genetics (ISHG) \\ Ahmadabad, India. 23-25 January 2013
}

\section{Background}

It is a generalized disorder appearing before adulthood, characterized by significantly impaired cognitive functioning and deficits in two or more adaptive behaviours. The present study was aimed to investigate the delayed development and psychological aspects in symdromic and non syndromic mental retarded individuals.

\section{Material and methods}

This study was conducted at B.M. Institute, Ahmedabad. The aetiology was ascertained after proforma studying and number of patients observed. The spectrum of causative conditions and contribution of genetic disorders was established. A total of 40 patients were observed in which 30 were male \& 10 were female between the ages of $3-11$ years. The various aetiological categories were: chromosomal disorders in 17, non chromosomal syndromes in 23. In which chromosomal disorders include Down syndrome, non-chromosomal disorders include delayed development and cerebral palsy.

\section{Results}

Among non syndromic mental retardation (NSMR) children; the walking is delayed by $1 \mathrm{yr}$ in $22 \%$ of children, 2 yrs in $57 \%$ of children, 3 yrs in $4 \%$ and $13 \%$ children were not able to walk. In syndromic mental retardation (SMR) walking is delayed by $1 \mathrm{yr}$ in $41 \%$ of children, 2 yrs in $23 \%$ of children, 3 yrs in $24 \%, 6 \%$ were not able to walk. Other developmental milestone such as sitting and speech in both syndromic and non syndromic mental retardation also showed the same pattern of delayed development as seen in the walking. In IQ, level the highest is SMR which is $44 \%$ severe \& $45 \%$ moderate while in NSMR 31\% severe \& 38\% moderate level were observed.

\footnotetext{
* Correspondence: zooldeptgu@satyam.net.in

${ }^{1}$ Gujarat Genetic Diagnostic Center (GenDiCe), Department of Zoology,

University School of Sciences, Gujarat University, Ahmedabad, Gujarat, India Full list of author information is available at the end of the article
}

\section{Conclusions}

The present investigation concluded that there was a delayed milestone in mental retarded children which was supported by IQ levels in this study.

\section{Authors' details \\ ${ }^{1}$ Gujarat Genetic Diagnostic Center (GenDiCe), Department of Zoology, University School of Sciences, Gujarat University, Ahmedabad, Gujarat, India. ${ }^{2} \mathrm{~B}$ M Institute of mental health, Ahmedabad-09, Gujarat, India.}

Published: 21 January 2014

\section{doi:10.1186/1755-8166-7-S1-P89 \\ Cite this article as: Shukla et al.: Mental retardation in younger children.} Molecular Cytogenetics 2014 7(Suppl 1):P89.

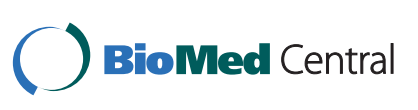

(c) 2014 Shukla et al; licensee BioMed Central Ltd. This is an Open Access article distributed under the terms of the Creative Commons Attribution License (http://creativecommons.org/licenses/by/2.0), which permits unrestricted use, distribution, and reproduction in any medium, provided the original work is properly cited. The Creative Commons Public Domain Dedication waiver (http:// creativecommons.org/publicdomain/zero/1.0/) applies to the data made available in this article, unless otherwise stated. 